\title{
Hachar un roble. Vascos y muerte en el Tandil decimonónico, Argentina*
}

\author{
Ax an Oak. Basques and Death \\ in the Nineteenth Century Tandil, Argentina
}

\author{
Marcelino Irianni Zalacain** \\ (D) https://orcid.org.0000-0002-0255-5080 \\ iehs-Igehcs-Conicet-Unicen, Tandil, Buenos Aires, Argentina \\ marcelino_iriani@yahoo.com.ar
}

Resumen: El 1 de enero de 1872, medio centenar de nativos asesinó a una treintena de extranjeros en Tandil (provincia de Buenos Aires). La matanza se llevó a cabo en apenas cuatro horas. El Sumario judicial deja al descubierto un episodio compulsivo en la conformación del grupo agresor, selectivo en cuanto a la etnia que más víctimas sufre y motivado desde ideas economicistas, sociales y hasta religiosas. Se trata de un ataque difusamente xenófobo, temprano, más bien rural y enfocado en carreteros y comerciantes vascos.

Palabras clave: xenofobia; compulsión; religión; comercio; vascos.

Abstract: On January 1, 1872, half a hundred natives murdered about thirty foreigners in Tandil (province of Buenos Aires). The killing took place in just four hours. The judicial summary reveals a compulsive episode in the formation of the aggressor group, selective in terms of ethnicity that suffers the most

* Organismos colaboradores: igencs-Conicet. iehs-Unicen, Tandil. Proyecto ConiCET: "Vivir en un margen occidental del mundo. Tandil, 1850/1870".

** Doctor en Historia. Líneas de investigación: la conformación de espacios de frontera.

cómo citar: Irianni Zalacain, M. (2021). Hachar un roble. Vascos y muerte en el Tandil decimonónico, Argentina. Secuencia (110), e1836. Dor: https://doi.org/10.18234/secuencia.v0i110.1836

cC Esta obra está protegida bajo una Licencia Creative Commons Atribución-NoComercial 4.0 Internacional. 
victims and motivated from economic, social and even religious ideas. It is a diffusely xenophobic attack, early, rather rural and focused on Basque carters and merchants.

Keywords: xenophobia; compulsion; religion; commerce; basques.

Recibido: 29 de febrero de 2020 Aceptado: 4 de junio de 2020

Publicado: 4 de mayo de 2021

\title{
INTRODUCCIÓN
}

\begin{abstract}
poco de comenzar el último cuarto del siglo xIx, un grupo de criollos A asesinó a 36 extranjeros en distintos puntos del partido de Tandil. Resulta difícil, planteado así, desestimar que se trató de un episodio xenofóbico. Sin embargo, leyendo el Sumario encontramos que buena parte de los apresados declaró haber sido "arrastrado" a la reunión del 31 de diciembre, donde se repartieron armas arengándose matar gringos y masones para defender a Dios y frenar el pisoteo de los nativos. Las declaraciones coinciden en que los que galopaban en la vanguardia -organizadores de la reunión mencionada-se encargaron de las muertes. Algunos de los hombres empujados a formar parte del grupo se desperdigaron oportunamente a lo largo de las cuatro leguas que cubrió el recorrido antes de regresar, a mitad de la mañana. Destaca la cantidad de vascos en el total de las víctimas, grupo étnico regional que gozó de buena recepción e imagen en el ámbito pampeano; que la mayoría de ellos fuesen ultimados en la zona rural no es menos relevante para desentrañar la maniobra de Jacinto Pérez, ideólogo del episodio; que los oficios de las personas asesinadas -carreteros y almaceneros-, distasen de cualquier competencia laboral con los lugareños, es otro elemento que orientó nuestro análisis.
\end{abstract}

${ }^{1}$ Departamento del Sud 1872. Asesinatos y robos en el Tandil el 1 de enero del corriente año y el Sumario Levantado por varios comisarios con motivo de los sucesos ocurridos el 1 de enero de 1872. Archivo del Museo Histórico del Fuerte Independencia de Tandil (en adelante, Sumario. MUHFIT), Argentina. 
que hacía cinco días que había llegado de los Tres Arroyos y donde es su domicilio y hallándose en el citado puesto de Santa Marina se presentó allí una comisión de cinco individuos a quienes no conocía el declarante y le ordenaron de marchar para aprehender a un hombre y saliendo con ellos lo llevaron a un bajo entre las sierras, lugar que no conoce donde había una reunión como de 40 hombres; que cuando llegaron era ya al salir el lucero, momentos antes de que se pusiera en marcha la gente, la cual era mandada por un viejito llamado Jacinto, cuyo nombre supo después. ${ }^{2}$

No contamos -salvo tensiones esporádicas relatadas por el danés Juan Fugl $^{3}$ - con documentos que pruebe malestar tandilense por la presencia extranjera. La arenga previa a las matanzas por parte del adivino Jacinto Pérez buscó exacerbar el sentimiento de los implicados, además de atemorizarlos. Su oficio, la fecha y la presencia reciente en el valle de un curandero con poderes sanadores como Tata Dios, bastaron para maquillar el episodio con aspectos milenaristas y dinamizar sus primeros pasos, con dudas en algunos implicados.

que hallándose [Casimiro Ramos] en su casa el 31 último se presentó en ella un tal Jacinto y lo invitó para una reunión que debía tener lugar esa misma noche, a la cual debía asistir pues de lo contrario se perdería él y toda su familia y no tendría misericordia; que habiendo oído su mujer esta conversación y temerosa de la amenaza que había hecho Jacinto, le instó al declarante que fuese aunque sea para ver. Que en efecto así lo hizo y se dirigió al otro lado de la Peñalverde, donde se hallaban reunidos de 40 a 50 hombres... Que después de estar allá, el tal Jacinto les proclamó diciéndoles que al día siguiente vendrían al Tandil a ocupar las bocas calles para que viesen como se iva a undir el pueblo de igual modo que el de Mendoza. Que al decir estas palabras, no le gustó ya el objeto de la reunión y le dijo a Jacinto le diese permiso para ir a buscar unos caballos que se le habían estraviado... que en efecto así lo hizo, salió en

2 Juan Crescencio Moreno. Sumario, f. 55. MUHFit, Argentina.

${ }_{3}^{3}$ Juan Fugl fue uno de los primeros inmigrantes a Tandil, a finales de la década de 1840. Proveniente de Dinamarca, pronto hizo esfuerzos para traer connacionales a la Argentina. Pastor de su comunidad, maestro escolar y desde el primer momento activo vecino para solucionar problemas locales, fue un precursor de la agricultura en un ambiente claramente ganadero, lo que le trajo problemas con algunos vecinos toda vez que las parcelas no estaban cercadas. Escribió sus memorias, que van desde la llegada a Tandil, hasta la década de 1870, cuando regresa a su país. 
busca de sus caballos y luego se fue a su casa a dormir, sin que supiese ya más nada de la reunión hasta el día siguiente. ${ }^{4}$

Ramos, citado por Jacinto Pérez a una reunión con ribetes místicos, debió morir años más tarde sin comprender que en 1872 estuvo a punto de quedar involucrado en una cruzada eclesiástica occidental. La dura Encíclica de Pío Nono ${ }^{5}$ confinado por los liberales al territorio del actual Vaticano, cruzó el Atlántico llegando a parroquias pampeanas como la de Tandil, donde sus curas señalaron a los masones como responsables del atropello. Para el común de los lugareños, distantes de la lógica socrática, si los extranjeros eran masones y atacaban a la Iglesia, atacaban a Dios. Este perfil religioso y místico que otorga también el calendario al episodio debió ser -aunque el cura se quejase de los criollos que no iban a la misa ni asentaban a sus familiares al nacer, casarse o morir-, un refuerzo en el discurso que intentaba sintetizar todos los males en aquellos extranjeros, especialmente los vascos. ${ }^{6}$ La masonería se había puesto en marcha tiempo atrás en el vecino pueblo de Azul (distante a 100 kilómetros de Tandil), donde habitaba una mayoría bearnesa ${ }^{7}$ confundida en ocasiones con los pirenaicos. Sin embargo, no hubo actividad masónica en Tandil hasta finales de 1872, momento en que surge a la sombra del dantesco acontecimiento. Resulta extraño, en cualquier caso, que los criollos implicados -algunos foráneos- supiesen identificar vecinos masones -si los hubo- que se mantenían en la clandestinidad institucional y simbólica al momento de las matanzas.

El episodio, aun luego de la lectura del Sumario, sigue mostrando zonas oscuras, algunas de las cuales hemos aclarado cercándolas con dudas e interrogantes. ¿Por qué vascos y no daneses o españoles cuando se arengó matar

${ }^{4}$ Casimiro Ramos. Sumario, fs. 52-54. muhfit, Argentina.

${ }^{5}$ La encíclica Quanta cura, 1864, anexa el Syllabus, donde se condena acciones del liberalismo. Apenas antes de las matanzas en Tandil, 20 de septiembre de 1870, los liberales le arrebatan al papa el último territorio, Roma, suceso trascendente que sigue siendo festejado por los masones italianos.

${ }^{6}$ El clima social imperante en una aldea que salía de los coletazos de la epidemia de cólera y fiebre amarilla, atravesaba una sequía de varios meses y, días antes, el paso de una manga de langostas, llevó a comparaciones insólitas como la presencia extranjera con las siete plagas de Egipto y hasta los jinetes del apocalipsis (Irianni, 2017).

${ }_{7}$ El grupo bearnés -un regionalismo francés como el gascón-, proviene de la misma región que los vascos continentales, confundiéndose sus límites geográficos e idiomáticos, compartiendo a menudo instituciones y ámbitos de sociabilidad. Azul, aún con estatus de pueblo en 1872 , se encuentra a 100 kilómetros al oeste de Tandil. 
gringos y masones?, ¿por qué en zonas rurales cuando abundaban extranjeros residentes en el pueblo?, ¿cómo explicar su falta de espontaneidad y una probada autoría de las matanzas en manos de apenas 10\% de los que marcharon esa mañana? Si varios de los implicados eran forasteros, pero se sintieron urgidos a una "cacería" desde el poblado hacia el norte arribando a un almacén de ramos generales distante a cuatro leguas desde donde regresan, ¿se trató de una coyuntura de tensión étnica mayor que hace erupción allí?, ¿no esconde contradicciones un episodio xenofóbico que nace compulsivo, se manifiesta contra la totalidad extranjera y se desenvuelve selectivamente en cuanto a sus víctimas?, ¿se puso en marcha a partir de una motivación económica específica de la elite, camuflada dentro de un aparente episodio xenofóbico? Las declaraciones de los implicados dejan al descubierto que apenas unos pocos -el ideólogo y quienes marcharon a la cabeza- tenían claridad supina de lo que iban a consumar. Repensamos un episodio complejo, con nuevas preguntas a un viejo documento.

Con estas consideraciones se analizó el episodio tandilense para discutir la inclusión del suceso en el renglón de la xenofobia pampeana. Utilizamos el Sumario mencionado como fuente principal de información. Consideramos el suceso como punta de un iceberg, la visibilidad de una tensión socioeconómica regional latente que incluía a los indígenas, criollos e inmigrantes llegados desde 1850. Analizamos la incidencia en este tipo de hechos espasmódicos, las características del escenario ${ }^{8}$ y la coyuntura. El suceso es coincidente con la redacción del Martín Fierro, de José Hernández, prueba irrefutable de tensión por la llegada de extranjeros que alcanzaban la inserción en un mercado de trabajo y de tierras en formación con claras ventajas frente a los nativos. ${ }^{9}$

Se analiza un episodio de dudosa categorización xenofóbica, temprano, marginal desde el punto de vista territorial, compulsivo y selectivo como el ocurrido en Tandil (centro de la provincia bonaerense). El Sumario que reúne la mayor información disponible sobre las matanzas de 1872 nos per-

8 Como veremos más adelante, nos referimos a un escenario en formación, precapitalista, inacabado, abierto, donde todo estaba por hacerse y la ausencia de mercados formalizados, permitía improvisar transacciones y aprovechar rentabilidades extraordinarias.

9 Santos (1995), al igual que otros autores que observaron el matiz xenófobo del movimiento, llega a la conclusión que las identificaciones y oposiciones construidas -nativo/extranjero- por los asesinos son incomprensibles si no es con arreglo a las políticas estatales de discriminación en torno a las cuales estos recursos simbólicos cobran sentido. 
mitió avanzar en el laberinto centenario de dudas sobre el suceso. Nos brindó, como un hilo de Ariadna, datos que hilvanados aportan luz para encontrar una salida no exenta de obstáculos. La información que nos brinda el Primer Censo Nacional (1869), los Libros de Solicitudes de Tierra de Tandil (18541880) y algunos periódicos porteños relatando un episodio con retazos recogidos por enviados tardíos, que desconocían el espacio o desde las plumas de intelectuales que nunca se trasladarían a la frontera, acerca datos de interés, apuntala comportamientos de reos y víctimas, aporta miradas frías a un Sumario salpicado con gotas de sangre y dudas en cada folio.

\section{APROXIMACIÓN AL TEMA DE ESTUDIO}

Repasamos, apretadamente, dos temas que consideramos clave para avanzar en el fenómeno que nos ocupa. La xenofobia y el episodio de las matanzas del Tandil. Ambos han sido analizados en distintos momentos, con enfoques y documentación variados. Respecto al primero, temor y fobia al extranjero fueron escasamente abordados en conjunto (Armus, 1984; Clementi, 1984; Wolf et al., 2001). La xenofobia, que no necesariamente va de la mano con criminalidad o violencia física, dedicó mayor atención a casos urbanos y tardíos. José Moya (1989) -uno de los pocos autores que intenta una mirada global al fenómeno- delimita, un par de décadas mediante, una hispanofobia decimonónica de una hispanofilia en torno al centenario patrio poniendo énfasis en la mirada de los inmigrantes desde la pluma de la elite nativa. Autores como Liernur (1984) observaron casos aislados en distintos sitios de la pampa, ya en el hacinamiento habitacional que forzaba la búsqueda de una casa propia para abandonar los conventillos (Páez, 1976; Suriano, 1984), ya en los bordes norteños de la pampa (Scobie, 1977, 1982), con los agricultores italianos acorralados en las colonias agrícolas por los arrendatarios (Gori, 1964; Gallo, 1983), o en la frontera sur. Desde la mirada de Clementi (1984) a Onega (1982), Bestene (1994) o el mismo Moya (1989), no faltaron reflexiones sobre los miedos a la inmigración de distintos sectores de la población nativa, como tampoco la figura de aquellos en la literatura y en el teatro, luego el cine, a veces estereotipados (Bestene, 1994; Irianni, 1997). Contamos, en menor medida, con la recuperación de casos aislados -no siempre relacionados con reacciones xenofóbicas aunque impliquen al menos un extranjero-que salpicaron de sangre el territorio, envueltos en dramas violentos junto a nativos o indígenas 
(Yangilevich, 2012). Las actitudes xenofóbicas aisladas han cortado transversalmente temas mayores como el de la inserción laboral (Sábato, 1983, 1985; Rodríguez Molas, 1982) o el de la integración-asimilación (Seefeld, 1984, 1985; Irianni, 2010), lo mismo que el de la política (Míguez, 1987).

Los trabajos académicos sobre las matanzas del Tandil de 1872 no abundan. Si buscamos el punto de inicio -salteando décadas de publicaciones poco sólidas- de una etapa historiográfica documentada sobre el tema, el primer texto que intenta un encuadre científico apoyado en documentación primaria es el de Nario (1976). Los trabajos de Rodríguez Molas (1982) y Richard Slatta (1985), al igual que recientemente Marcelino Irianni (2017), amplían la mirada a esa coyuntura agraria bisagra (en torno a la década de 1870), el ocaso del gaucho y el fin de una era ganadera que tensaba un mercado de trabajo en formación. Un trabajo interesante -aunque en la misma línea de análisis- que observa que no fue casual la matanza en una zona de tensión entre una sociedad primitiva y otra moderna, pertenece a Oddone y Granate (2007). Con miradas de alguna manera complementarias a lo planteado por Hugo Nario (1976), hubo progresos destacados desde los trabajos de Miguel Palermo (1978), John Lynch (2001) y Lorenzo Macagno (2002).

Clara Lida (1998) y José Santos (2008) dedicaron su esfuerzo a un aspecto interesante y polémico del episodio, como es la xenofobia. ${ }^{10}$ En textos como el de Hugo Nario (1976), Miguel Palermo (1978) y Lorenzo Macagno (2002), los sucesos encajan oportunamente -en ocasiones en un segundo plano-, desde encuadres teóricos como bandolerismo y milenarismo. La documentación fue acaso la variable más estática de esta secuencia historiográfica. No eran épocas ni Tandil el sitio ideal para que el Estado registrase la realidad ni la reflejaran y resguardaran los periódicos, salvo desde la lejanía de plumas porteñas. El trabajo de Lynch (2001) no agrega claridad al episodio en cuestión, aunque suma observaciones provenientes de los periódicos europeos. El Sumario que se trabaja en el presente texto sigue siendo el ma-

10 Esta autora sostiene, sin otra prueba de que Martín Fierro dijese "pulpero habilidoso", abusivo y usurero, que "nos tenía apuntaos a todos / con más cuentas que un rosario" que aquella resistencia primitiva, el objetivo mismo, era deshacerse de ellas (Lida, 1998). Es altamente probable que aquellos almaceneros no fiasen a los criollos pobres y menos a los escasos gauchos. En última instancia, la deuda por un par de copas o comida, difícilmente condujese a matar a 18 personas para anularlas. Distintos valores envolvían el universo del almacenero/ acopiador frente al terrateniente, lo que potencialmente amerita a pensar en una estrategia para deshacerse de los libros de cuenta. 
nantial ineludible donde abrevar información. La interpretación del episodio se pudo superar, de alguna manera, contextualizando la época, abriendo la mirada a un universo social y económico mayor (Irianni, 2017), apelando a lo interdisciplinario.

\section{EL ESCENARIO}

Tandil nace en 1823 como fuerte militar de avanzada en tierras indígenas, apenas siete años después de declarada la independencia argentina. Un país amorfo y una nación dispersa comparable a piezas de distintos puzles que dejó la disolución de los virreinatos y capitanías, derramó violencia interna y externa -con breves intermedios de calma- hasta 1880. Abocados a ordenar el territorio y conflictivos límites geográficos y políticos al norte, una población escasa, recursos modestos y levas permanentes de soldados obligaron a los distintos gobiernos a pactar acuerdos con las sociedades indígenas ubicadas a sus espaldas. El Río Salado era un Rubicón que cortaba en dos la provincia bonaerense y acaso el país, toda vez que desde allí el territorio era considerado indígena hasta el extremo patagónico. De alguna manera, Juan Manuel de Rosas fue un Julio César pampeano que lo cruzó en dirección a la región de los bárbaros, los aquietó y regresó a la ciudad porteña para adueñarse del poder hasta su caída en 1852 .

Uno de los dos nudos serranos que rompen la monotonía pampeana es Tandil, fruto de la primera campaña militar argentina -había habido incursiones breves durante la colonia- para trazar una línea de frontera, imaginaria si tenemos en cuenta la insignificancia de los destacamentos en la vastedad del territorio. En una elevación, a modo de acrópolis, el Fuerte Independencia se rodea de viviendas de colonos bosquejando una aldea que demandará el estatus de pueblo desde 1840, animada por la llegada de inmigrantes y provincianos. Ello ocurrió, en buena parte, gracias a la "pax rosista".

${ }^{11}$ Como la pax romana en territorios conquistados, la pax rosista consistió en pactos de no agresión con las sociedades indígenas. Ello contemplaba la entrega trimestral de mercadería a los caciques además de un número determinado de yeguarizos y la exigencia de participación de indígenas en campañas militares posteriores. Las parcialidades que aceptaban las condiciones se convertían en aliadas, lo que las separaba de aquellas consideradas amigas, con menos prerrogativas, pero más margen de acción y las hostiles, ubicadas en la periferia de la pampa húmeda. 
Una década después de la revolución de mayo de 1810, los criollos tomaron conciencia de que el corte del camino Buenos Aires-Potosí -altamente rentable para el puerto rioplatense- no era factible de suplantarse con la herencia del comercio hispano. Sin flota ni recursos para mejorar el puerto, los ingleses tomaron la posta consolidando una larga tradición de contrabandos en ese mercado americano agrietado y vetusto en su obstinación monopólica de ventas con Cádiz. La opción criolla estaba al sur, donde miles de cabezas de ganado que se habían reproducido en forma salvaje desde 1700 ofrecían una oportunidad inigualable a los ganaderos que se lanzan al comercio de cueros para fábricas europeas y tasajo para enclaves esclavistas.

El mismo Rosas recorre en $1833^{12}$ el territorio que luego conformaría la provincia bonaerense negociando con algunas parcialidades (véanse Jong, 2016; Ratto, 2003) y expulsando a otras. Detrás del avance del ejército, unos pocos criollos se adueñaron de terrenos de cinco leguas cuadradas, apenas delimitados con mojones de piedra rápidamente tapados por los pastizales. Esa distensión, la ocupación estacional de criollos pobres en épocas de juntada de caballos o vacas, como también de doma, no asfixió inicialmente a las parcialidades indígenas ni a los criollos, que podían cazar fauna silvestre o tomar ganado por su cuenta asentándose en lo que se denominó Tierra Adentro, el amplio espacio ubicado más allá de la frontera. Ello perduró aún con el aumento de población extranjera y provinciana en proporciones modestas hasta la década de 1860, agravándose el paisaje socioeconómico recién en la década siguiente. La tensión entre criollos, comparable al heterogéneo colectivo plebeyo romano, se inicia con levas que arrancaban a los criollos humildes de sus familias para cubrir la línea de frontera durante periodos mayores a cinco años, generalmente sin pagas ni relevos.

A mediados de ese siglo, el Viejo Mundo replantea necesidades e intereses impactando en los países nuevos. El ovino demandado por Inglaterra pastaba sin mayores demandas en la pampa rioplatense. Los pastos y el clima, que no incluía trashumancia, eran un plus atractivo. A falta de nativos que conocieran el manejo ovino, toda vez que el criollo era especialista en equinos y en arreo de vacunos, pastores vascos, franceses e irlandeses comenzaron a llegar desde fines de 1840 y principios de 1850. La ausencia de merca-

${ }^{12}$ En esa excursión, Rosas recorre el fuerte San Serapio de Azul -fundado por su orden en 1831-, espacio importante a este trabajo, dado que desde allí viajará a instalarse a Tandil el curandero Gerónimo Solané. 


\section{Mapa 1. Ubicación de Tandil en una zona de frontera}

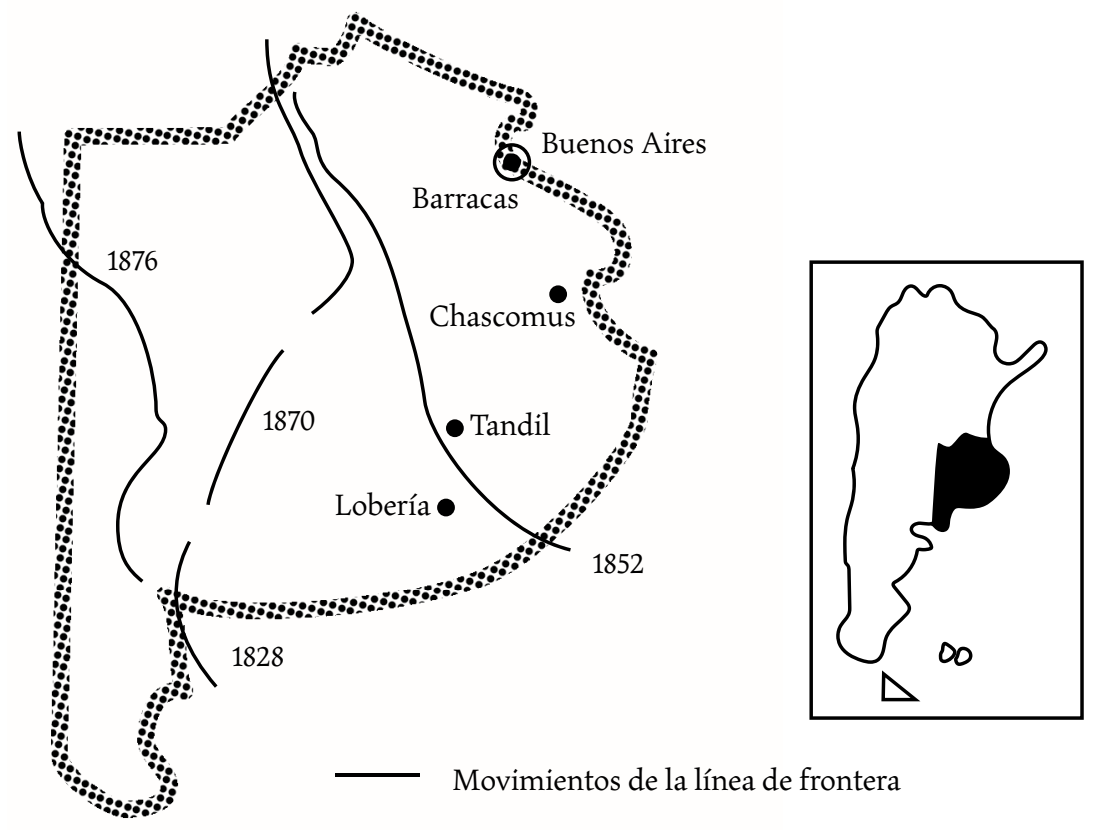

Fuente: elaboración propia.

dos de tierra y trabajo les permitió ofrecer un trato novedoso en Sudamérica como era la aparcería. Su rentabilidad los condujo a adquirir tierras medianas o chacras, llegando algunos a ser propietarios de grandes extensiones y majadas. Algunos vascos pioneros amasaron fortunas en este rubro, cuando los contratos eran favorables al que conocía el oficio. Otros, en el mismo polo económico, lo hicieron trasladando lana en sus carretas, hospedando huéspedes que no tenían casas en sus fondas y acopiando lanas y cueros en almacenes que lograban pingües ganancias vendiéndolo luego a precios de exportación. El criollo, especialmente ese puñado reconocido como gaucho, ${ }^{13}$ compartió

${ }^{13}$ Aquel periodo, signado por estancias de vacunos abiertas junto a las primeras producciones cerradas de ovino, con galpones y cercados, con distintos puestos que suplantaban un único rancho o vivienda en la mitad del anterior modelo de latifundios, cimenta la problemá- 
el ocaso de su vida económica y social junto a los terratenientes absentistas como los que rodeaban el almacén de ramos generales de Chapar, asesinado en 1872. En sus memorias, el agrimensor Alfred Ébelot nos lega el testimonio -inicios de 1870- de las tareas de un comercio rural vasco de entonces. Si en vez de hablar de un vasco anónimo mencionase a Juan Chapar no dudaríamos que es información real y objetiva. Si fuese Chapar, que antes de irse al almacén de las matanzas estuvo asociado con Alchourrut en un comercio grande situado en el borde sur de Tandil, tampoco sería objetable. Con esos pocos datos, estaríamos frente al diagnóstico que provocaría un colapso de dimensiones dantescas en ese almacén el 1 de enero de 1872.

Me conchabé con otros compañeros de viaje en una casa introductora como peón para descargar carros. Todos los vascos principiamos de este modo. $\mathrm{Mi}$ patrón se fijó en mí, me elevó a dependiente y me habilitó para comprar esta pulpería, en que estamos a medias. El oficio es bueno. Solamente mi patrón, que es muy inteligente, atrevido y jugador, quiere enriquecerse de golpe. Usted sabe mejor que yo que la venta de ginebra, de bota, riendas, géneros y de todo cuando necesita el gaucho, no es nuestro verdadero negocio. Sirve solamente de pretexto de nuestras operaciones en lanas y cueros. Fiamos durante todo el año al gaucho y al estanciero. Nos pagan cuando venden los frutos del país. Es una especie de comercio de intercambio, siempre ventajoso para quien tiene suficiente dinero. Además, como nuestros vecinos están con nosotros en continuos tratos, somos los compradores naturales de todo cuanto tienen que vender (Ébelot, 1890/2001, p. 158).

Las sociedades de frontera, desde un enfoque amplio y con todos sus actores escena, toman volumen un par de décadas después de fundados sus cimientos, generalmente castrenses. La demografía era su talón de Aquiles. El mismo Rosas hizo trasladar desde la ciudad de Buenos Aires a todas las mujeres de dudosa reputación a efectos de impulsar el crecimiento demográfico en una zona mayormente masculina. La papeleta de conchabo que surge en la misma época, era un certificado de trabajo extendido por un estanciero a un

tica que aquí se analiza. El criollo se aferraba como cliente de un estanciero para evitar ir a la milicia. Esas eran las opciones de una mayoría: mercado forzoso de trabajo o las armas. Para ampliar sobre el gaucho y sus diferencias con el criollo, véase Mayo et al. (1987). 
criollo y que debía presentar cada vez que el ejército levaba futuros soldados en almacenes y pulperías, aunque también en los caminos.

El censo levantado en 1854 en una provincia bonaerense aún imaginada, concedió a la campaña una población de 180512 habitantes. Los argentinos nativos provenientes de otras provincias constituían $12 \%$ de esa cantidad y los extranjeros, que sumaban 15532 , representaban 9\% del total. ${ }^{14}$ Quince años más tarde, el primer Censo Nacional mostraba que por cada 1000 habitantes, 801 eran argentinos y 199 extranjeros (557 varones y 443 mujeres). ${ }^{15}$ El número de vascos que arroja dicho Censo de 1869 para Tandil (266) representa $56.47 \%$ del total de españoles y franceses (471) del partido. Los vascos alcanzaban $5.46 \%$ del total de esa población (4 870 habitantes).

La historiografía sobre aspectos atomizados -indígenas, criollos e inmigrantes- que la mirada actual reúne para comprender su dinámica, atraviesa una época dorada desde 1980, tomando celeridad en las últimas décadas. ${ }^{16}$ Estas sociedades se caracterizaron por habitar espacios nuevos, lejos del control del Estado y, por tanto -excepto por las milicias- de sus servicios esenciales, viales como sanitarios o de organización de mercados de tierras y de trabajo. Una pampa sin árboles, un clima riguroso y la ausencia de caminos, dificultaban la vida cotidiana, con déficit de viviendas y elementos básicos para cercar propiedades y encerrar animales. Con problemas para conseguir un médico y un boticario, pero también un cura hasta entrada la década de 1860, el control de las comisiones municipales que surgen a finales de 1850 intentaba equilibrar el poder ilimitado de los jueces de Paz. Con fluidez, aunque envueltos en cifras pequeñas, los inmigrantes -entre los que hubo muchos vascos y daneses- aprovecharon la pax rosista que mantenía a los indígenas en cercanías de guarniciones militares, como la de Azul, a 100 kilómetros de Tandil. Ambos pueblos reciben extranjeros que se insertan en un abanico de oficios, ya como carpinteros, albañiles, ladrilleros u hojalateros para la construcción de viviendas o fonderos que ofrecen comida y cama a aquellos que construían su casa en el tiempo libre. No faltaron pastores, horticultores y labradores, como tam-

${ }^{14}$ Registro Estadístico del Estado de Buenos Aires, 1855, dirigido por Manuel Trelles. Archivo Histórico Provincial, La Plata (en adelante AHP), Argentina.

${ }^{15}$ Primer Censo Nacional, 1869. Sala x. Archivo General de la Nación (en adelante AGN), Argentina.

${ }^{16}$ Imprescindibles, algunos avances desde 1980 en historia colonial y luego agraria, se pueden ver en Garavaglia (1992, pp. 41-57; 1995, pp. 11-319; 1999, pp. 11- 46). También Fradkin y Gelman (2004). En el campo indígena y la frontera, véase Mandrini $(1992,1997)$. 
poco empleados -o independientes- indispensables en fondas y hoteles que lavaran ropa, cosieran, plancharan y cocinaran para un universo masculino, joven y soltero que sobresalía entre los inmigrantes.

Gerónimo Solané, alto, encorvado, de cabello abundante y vestido con un poncho indígena y sombrero, era un curandero que llegó a la zona de Azul desde Santiago del Estero según algunos; desde la selva entrerriana, según otros. Ambas zonas, cualquiera que fuese, eran de sólidos cimientos indígenas y reconocido misticismo en manos de chamanes y curanderos. Al comenzar una década bisagra como la de 1870, en la que el ejército regresaba triunfante, aunque portando la fiebre amarilla desde el Paraguay y el Estado podía girar sobre sí mismo para atender su flanco sur, Gerónimo Solané es llevado a Tandil por un terrateniente para que se convierta en el curandero particular de su esposa. Solané, como si mirase el paisaje de Tapalqué o Azul, pueblos donde había practicado sus curaciones, observaba tantos caballos como ovejas, muchos criollos buscando un ganado cimarrón que escaseaba, comercios de ramos generales florecientes. El calendario colgado en el almacén del vasco Juan Chapar señalaba que era 20 de noviembre de 1871. Faltaban apenas 40 días para que el pueblo amanezca con la noticia de la muerte de 36 extranjeros.

\section{EL EPISODIO}

La gente de Tapalqué y Azul se cruzaba con indígenas, criollos y bearneses cuando se trasladaba hasta el rancho de Solané buscando alivio en su salud física o psíquica. Como luego en Tandil, lo visitaban centenares de enfermos y tullidos, quedando registrados en el Sumario y también en textos que hacen referencia a sus habilidades y/o dones para la curación. ${ }^{17}$ Ramón Gómez, estanciero tandilense, viajó a buscarlo en noviembre de 1871 para que se instale en su establecimiento ganadero (La Argentina) y alivie las jaquecas de su esposa Rufina Pérez. Ya en el rancho hospital (un puesto de la estancia), buena parte de sus pacientes azuleños se trasladaron para continuar tratamientos, sumándose a otros tantos -cifras que rondan las 300 personas- de la zona.

${ }_{17}$ Entre otros, el periodista contemporáneo Rafael Barreda -aunque con inclinaciones a explayarse sobre actitudes psíquicas del curandero- hizo referencias a ello a principios del siglo xx. Caras y Caretas, núm. 712, Buenos Aires, 25 de mayo de 1912. 
El 31 de diciembre de ese año, apenas un mes después de que arribase Solané a la estancia La Argentina, Jacinto Pérez, conocido como el adivino, reúne medio centenar de criollos -algunos foráneos ${ }^{18}$ - en las afueras de Tandil. Como vimos, varios fueron convocados en forma compulsiva, según declaran ante el juez Isla. Antes de comenzar el cruel itinerario, Jacinto Pérez arenga a matar "siendo gringos y masones, también vascos", al tiempo que reparte armas y cintas punzó. ${ }^{19}$ Con idéntico discurso con el que se arrastró personas a la reunión, Jacinto anuncia que ese día se inundará el pueblo y nacerá uno nuevo, donde vivirán aquellos que colaboren en la pueblada que los reunía. Quienes se negasen -y sus familias- sufrirían las consecuencias. Prueba de la compulsión -más allá de las propias declaraciones-, es que la cifra inicial de jinetes reunidos se desgranase a lo largo de las cuatro leguas que cubren la plaza de Tandil y el almacén del vasco Chapar. Ese comercio marcó el final de la marcha y retorno de los que seguían -con más o menos complicidad o temor a desertar- envueltos en la misión encomendada por Pérez.

A las cuatro de la mañana se escucharon los primeros gritos en la plaza del pueblo. A partir de ese momento, asesinan a 36 personas, incluyendo mujeres y niños de corta edad. Alrededor de las diez de la mañana, los reos que volvían de lo de Chapar se encuentran con la guardia y vecinos armados que salieron tardíamente $e^{20}$ en su búsqueda.

El origen de las víctimas no oculta el objetivo étnico de esa jornada. Dos italianos, dos ingleses $y$, el resto, vascos. ${ }^{21}$ No es un tema menor que al

${ }^{18}$ El sitio de la reunión se menciona en el Sumario como la Peñalverde. Estamos de acuerdo con Lynch (2001, p. 82) cuando asocia el código rural con la flamante movilidad de la población rural, incluso entre provincias. Entre los asesinos de ese 1 de enero, muchos eran forasteros.

${ }^{19}$ La cinta punzó identificaba a los federales principalmente en la época de Rosas. Aquel distintivo y el color de algunas de sus vestimentas los separaba socialmente de los unitarios, vestidos de azul francés. Este detalle que tuvo en cuenta Jacinto Pérez para cohesionar al grupo a una etapa en la que el criollo era tenido en cuenta por el gobernador y sus funcionarios y en los que no había aún una disputa de los inmigrantes frente a trabajos estacionales, se prueba a partir de la compra de cinta uno o dos días antes en un comercio tandilense, por hombres de su entorno.

${ }^{20}$ Nario (1976) señala declaraciones en las que se observa claramente ese accionar del comandante Ciriaco Gómez (hermano de Ramón que cobijó a Solané en su estancia), ya haciendo formar la guardia reiteradamente, revisando armas, dejando correr el tiempo que era crucial según informaban los primeros vecinos que dan cuenta de la correría sangrienta antes de las seis de la mañana.

${ }^{21}$ Llama la atención que una decena de carreteros vascos que esperaban la mañana en las afueras del poblado y luego tres familias de almaceneros -una inglesa y dos vascas-, reunieran casi la totalidad de las víctimas. 
Mapa 2. Itinerario de las matanzas. Tandil y su zona rural norte

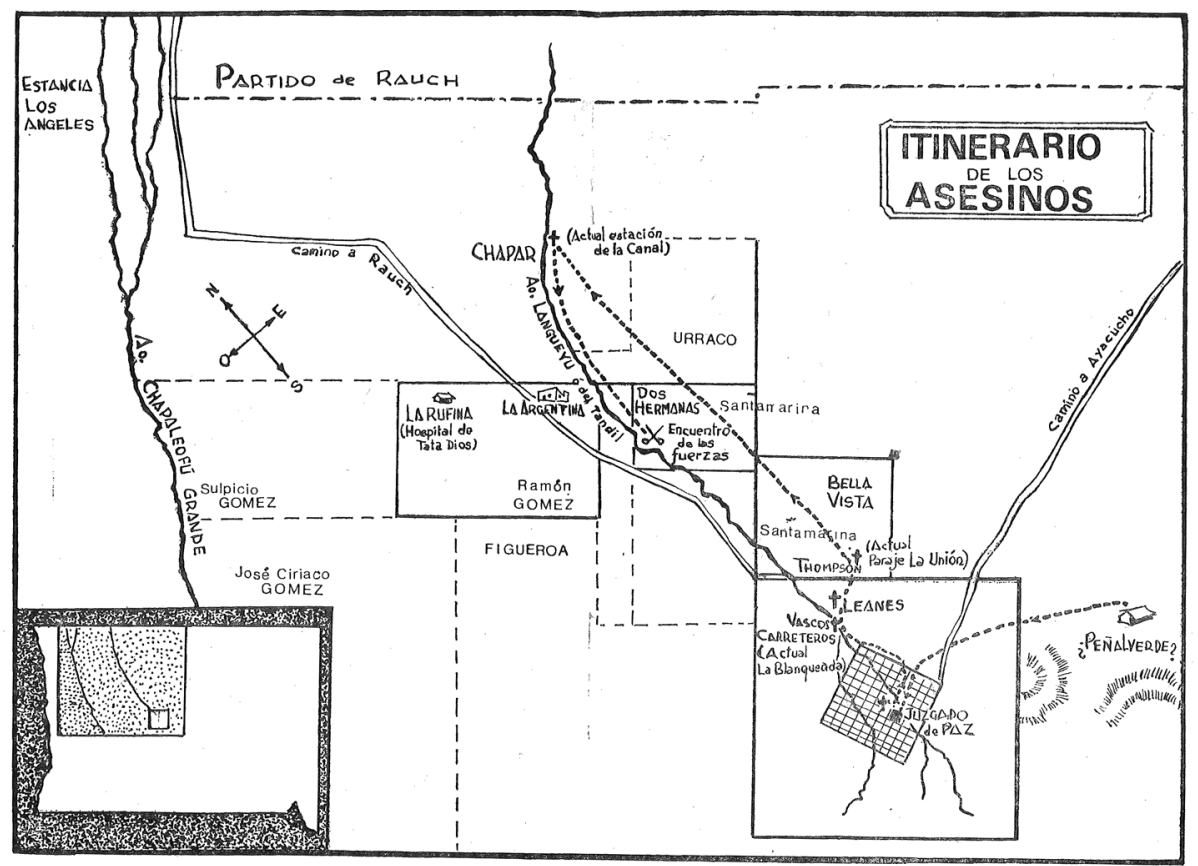

Fuente: mapa cedido personalmente por Hugo Nario, extracto de su libro Tata Dios. El mesías de la última montonera, Plus Ultra, 1976. 
encontrarse arroyo por medio con la guardia que iba tras ellos, uno de los reos apellidado Rodríguez levanta sus brazos festejando el éxito de la empresa. Los asesinos vivaban haber cumplido con la patria, limpiando el mundo de masones mandados por Tata Dios, según les había dicho Jacinto Pérez. La historiografía no se detuvo lo necesario, en casi un siglo y medio, a analizar ese momento crucial del episodio.

estando ya reunidos vio venir un grupo de cuatro hombres armados del lado de la estancia de Don Ramón y lo cual reconocidos que fueron, resultaron ser Gerónimo Solané y otros más que venían a reunirse a la gentes mandándose a que se ubiquen en la retaguardia; que después se puso en movimiento toda la fuerza avistándose a corta distancia a los que se perseguían, los cuales tendieron su línea del otro lado del arroyo del Tandil y adelantándose Pedro Rodríguez fue preguntado "por que andaban asesinando", contestando él "que mataban por orden de Tata Dios a los gringos y masones porque los sacrificaban o perjudicaban" y que gritándole entonces el Comandante Gómez que dijese a esa gente que se rindiese porque deno [sic] los peleaba, dio vuelta y pasando la línea de los suyos dieron vuelta, siendo entonces cargados..., que durante la persecución sólo conoció a Rodríguez, un tal Jacinto, un moreno Leandro y Juárez, capataz del señor Santa Marina, que todos ellos estaban armados. ${ }^{22}$

que antes de la pelea y formada la línea de los criminales, se adelantó el sargento Pedro Rodríguez pretendiendo parlamentar con el comandante Gómez a quien le dijo que las muertes que habían cometido las hacían por orden del médico dios quien les había mandado concluir con los estrangeros masones; que hallándose a espaldas de la guerrilla que mandaba el declarante, el tal médico dios contestó a la aseveración de Rodríguez diciendo que era falso, que él no había mandado a matar a naides [sic] y se replegó a los lanceros, desapareciendo en seguida, siendo preso por orden del comandante Gómez en la estancia de la Argentina donde se le encontró..$^{23}$

Varios detenidos y testigos, entre ellos capitanes y tenientes, declaran ante el juez que "Tata Dios salió de la retaguardia de la policía gritando

${ }_{23}$ Teniente alcalde Teófilo Urraco. Sumario, fs. 202/203. MUHFit, Argentina.

${ }^{23}$ Teniente Lisandro de la Cuesta. Sumario, fs. 202/203. MUHFIт, Argentina. 
‘ ¡Mienten!, yo no mandé a matar a nadie’.”24 Estaba allí, a las once de la mañana, armado y con sus ayudantes del hospital donde atendía, colaborando con la partida reunida por el comandante Ciriaco Gómez. Hubo desconcierto y desolación entre los reos, paralizados ante la negación pública de Solané que según Jacinto Pérez los convocaba a realizar ese ensayo de juicio final. El teniente Urraco ordenó atacar impactando, casualidad o no, las primeras balas y sables sobre los cabecillas Jacinto Pérez y Rodríguez. Varios criollos lograron huir, más allá de su culpabilidad no probada, perdiéndose entre la hierba alta de un caluroso enero. No es menor el detalle de que Solané se sumara a la guardia y menos que, luego de aclarar que no tenía relación con las muertes, se fuese al rancho hospital cuando bien pudo huir del partido.

Dos eventos de clara tensión local -probablemente poco tenidos en cuenta por los criollos comunes- se sumaban a la mística del milenarismo y vaticinios de inundaciones. La arenga del adivino en su rancho del paraje La Peñalverde urgía matar -en nombre de Tata Dios- gringos masones y vascos. Sin embargo, ningún detenido ni testigo reconoció el vínculo entre Tata Dios y Jacinto Pérez, una de las preguntas repetidas por el juez. Por ello, además de que Solané y tantos otros comentaban el desplazamiento laboral de los criollos por parte de los extranjeros, al final del mismo día de los asesinatos se grabó a fuego el rótulo de las matanzas de Tata Dios. ${ }^{25}$ Solané fue culpable sin ser juzgado, ${ }^{26}$ asesinado por la ventana de la celda la noche de reyes cuando el comandante Ciriaco Gómez liberó la zona alejando a los 40 extranjeros que habían improvisado un rondín armado. Fugl, en sus memorias y luego algunos descendientes de aquellos inmigrantes en armas, ratificaron que la ejecución quedó en manos de un vasco. También que el guarda recordase que la ventana había quedado sin trabar, pudiendo abrirse con el viento. No hubo sospechosos ni detenidos por el asesinato del curandero en su celda. El 17 de enero, llegó el juez Isla desde Buenos Aires y comenzaron los interrogatorios. Partiendo de la cifra de medio centenar de jinetes, descartando los que huye-

24 Teniente Lisandro de la Cuesta. Sumario, f. 195. MUHFIT, Argentina.

25 Es frecuente, aún hoy, escuchar comentarios sobre las matanzas de Tata Dios, pese a que Nario en 1976 lo tildó de chivo expiatorio de una sigilosa maniobra de la elite local.

${ }^{26}$ El hermano de Juan Chapar, también vasco, se presentó el 26 de febrero de ese año con el auspicio legal del Doctor de los Llanos... planteando que, si bien los cabecillas invocaban el nombre de Tata Dios, "nada hace presumir que éste fuera el jefe del movimiento". Sumario, f. 471. MUHFIT, Argentina. Es altamente probable que conociese las operaciones comerciales y clientes destacados de su hermano, además de que habían desaparecido los libros. 
ron y los que murieron en el enfrentamiento, el 18 de junio hubo catorce absueltos y se sentenció a fusilamiento a dos reos, ${ }^{27}$ además de siete condenados a quince años y dos, a nueve años. ${ }^{28}$

\section{DOCUMENTACIÓN Y METODOLOGÍA}

La documentación que hemos analizado se encuentra en el Museo del Fuerte Independencia de Tandil, reunida en un cartapacio que contiene alrededor de 1200 fojas y se titula "Departamento del Sud 1872, Asesinatos y robos en el Tandil el $1^{\circ}$ de Enero del cte. año y el Sumario Levantado por varios comisarios con motivo de los sucesos ocurridos el $1^{\circ}$ de enero de 1872". En el Archivo Histórico Municipal (en adelante AHM), la información sobre el caso no es la esperada, aunque se complementa con ella sobre la vida en el Tandil de la época, las decisiones de la corporación municipal, la venta de tierras y las mejoras en el poblado. Lamentablemente, la correspondencia para el Juzgado de Paz de ese año que se halla en el АнM de Tandil es escasa e incompleta. Existen algunas publicaciones de La Tribuna, de enero de 1872, así como de La Nación y La República de septiembre del mismo año. Las distancias alteraban -con o sin intenciones- la crónica de un episodio como el que nos ocupa aquí. La virulencia política de un Buenos Aires que atravesaba la presidencia de Sarmiento luego del mandato de un Mitre liberal que pujaba desde la oposición para no perder ningún enfrentamiento, aun de sus bases más lejanas como las de Tandil, nos ubican delante de informaciones de escaso valor sobre el caso de Tata Dios. El fusilamiento de Lasarte y Gutiérrez en septiembre es un claro ejemplo. Tandil no tenía periódicos y el corresponsal anónimo de La Nación -seguramente partidario de Mitre- dedicó buena parte de aquellas columnas a recuperar la imagen de la gente del juez Figueroa, quien se vio obligado a renunciar. ${ }^{29}$

27 “Ejecución de los asesinos del Tandil”, La Tribuna, 19 de septiembre de 1872, artículo tomado del diario La Nación del 14 de setiembre, redactado por un testigo presencial del acontecimiento.

${ }^{28}$ Carta del comisario Brid al juez del Crimen del Departamento del Sud, 18 de junio de 1872. Sumario. MUHFit, Argentina.

${ }^{29}$ Para ampliar sobre la nota véase La Nación, 14 de septiembre de 1872 o Nario (1976, pp. 204-209). 
Un enfoque holístico que abarque la totalidad de los actores es vital para concluir sobre un episodio xenofóbico concreto y sus dimensiones, pero también incluir el mayor número posible de involucrados de alguna manera en el mismo. Es inevitable calibrar alternativamente la mirada a occidente y el país, la región, el poblado e incluso los acontecimientos en torno al rancho hospital. Aunque se impone una mirada cualitativa y nominal, esta descansa en los datos del Primer Censo Nacional $(1869)^{30}$ que arrojan guarimos sobre extranjeros -entre ellos vascos- y nativos. Al momento de analizar el contexto, bosquejar una coyuntura, identificar procesos y ritmos de los mismos, hemos tenido en cuenta los avances de nuestros colegas de historia agraria, indigenistas, historia política, especialistas en juzgados, entre otros. Así, el escenario es la región de Tandil, epicentro del suceso que, según algunos indicios, bien pudo ser otro pueblo vecino. ${ }^{31}$

$\mathrm{El}$ arco temporal es flexible. Se pone atención en el periodo 1860-1872. Allí comienzan a acelerarse los cambios socioeconómicos que impactan en la aldea como un meteoro una década después. Comprendiendo la coyuntura, nos centramos en los meses de noviembre de 1871 a enero de 1872. Las matanzas culminan -incluyendo el asesinato de Tata Dios- el 6 de enero. Los juicios se llevan a cabo del 17 al 30 de ese mes y el fusilamiento de los únicos dos apresados, Gutiérrez y Lasarte; un tercero, Villalba, muere en el calabozo el 13 de septiembre.

La información de las declaraciones en el Sumario es variopinta. Algunas respuestas son parcas y firmes, por ejemplo ante la pregunta de si conocían a Jacinto Pérez o a Jerónimo Solané; otras merecen ser leídas con detenimiento en busca de indicios que apuntalen datos interesantes sobre lo sucedido. Los límites de esta documentación devienen de la cantidad de testigos y procesados que almidonan con rígidos cuestionarios la calidad que hubiese presentado un número menor de personas implicadas. El descuido de

${ }^{30}$ Cédulas Censales del Primer Censo Nacional de la Argentina, 1869. Buenos Aires. Sala x. AGN, Argentina.

${ }^{31}$ Declaración de Caballero, vecino de Azul que llega a Tandil un par de días después de las matanzas y declara, mientras vende su lana, que aquello estaba organizado para el 10 o 12 de enero en Azul y se adelantó en Tandil. Sumario, f. 4. MuHFiт, Argentina. Este documento cuenta con varios informes solicitados a comisarios de la región, en torno a otros curanderos que pudieran rebelarse, indígenas movilizados y búsqueda de prófugos. El episodio fue local. Aunque igual de irracional, si se hubiese desatado en Azul allí sí había una logia masónica desde hacía unos años. Luego del episodio tandilense, los azuleños apadrinan una logia en Tandil a mediados del mismo año 1872. 
no llamar a declarar a la esposa de Jacinto Pérez -ya viuda cuando comienza el juicio- es un dato de peso, principalmente porque casi todos los involucrados lo mencionan. El español Ramón Santamarina ${ }^{32}$ tampoco fue citado. Su compromiso en el episodio apuntala nuestra hipótesis de que no se trató de una xenofobia clásica y no sólo por su calidad de extranjero. La noche en la que asesinaron al curandero en un calabozo del juzgado, a la una de la mañana, Santamarina tomaba café con el cura y el coronel Benito Machado en la sala de adelante. Como si faltasen motivos para citarlo, hubo empleados suyos entre los criollos armados -Juárez- y algunos prófugos fueron encontrados escondidos en habitaciones y galpones de una de sus estancias.

\section{¿MATAR MASONES, VASCOS O UN VASCO ACREEDOR?}

No tiene conocimiento de los asesinatos por no haberlos presenciado; que el día que se indica el declarante andaba campiando tres bueyes y cuando regresó a los carros que estaban cargados frente a la casa de negocios del finado don Juan Chapar, vio una gente que cruzaba por el campo y acercándose dos individuos conoció a María Pérez, no fijándose qué arma tenía. Que el otro llebaba una lanza; que María Pérez le dijo "Amigo, su patrón queda muerto. Y el otro, a quien no conoce, también le dijo: "ahí quedan todos los masones muertos". ${ }^{33}$

No queremos cerrar estas páginas sin reflexionar sobre un vocablo -caro a la discusión del presente trabajo- entonces novedoso y complejo, al menos en un periférico Tandil de 1870: masón. Con aire acusador, aquella pequeña palabra flotó en el ambiente tandilense los días anteriores a la matanza. ${ }^{34} \mathrm{La}$

32 Ramón Santamarina, gallego nacido en Orense y que viaja a Argentina en 1840, con catorce años, logra adquirir un capital importante en menos de dos décadas. Luego de algunos trabajos, compra una carreta, conformando hacia 1860 una tropa de más de catorce vehículos en la que traslada mercadería y nuevos vecinos a distintos pueblos. El Estado le abona -como era costumbre- con tierras, llegando a conformar miles de hectáreas con establecimientos extraordinarios en las afueras del Tandil. Una de sus estancias rodeaba el predio del almacén de Chapar, comerciante que fiaba y adelantaba los sueldos de los peones a cambio de cueros y lana que se obligaban a entregar terratenientes como Santamarina. Los montos de pagos realizados y cueros que no siempre llegaban, estaban registrados en los libros rotos de Chapar.

33 Avalario Coria. Sumario, fs. 191-192. MuHFit, Argentina.

${ }^{34}$ Sumario. Carlos López declara que se unió a la partida de milicianos y vecinos armados y que hacía días corría la voz de que para el primero iba a haber una revolución, ignorando que podría tener de cierto semejante dicho. 
prédica del párroco grabó a fuego la consigna de masones atacando la religión $y$, por ende, a Dios. Eso era suficiente, aun arañando la superficialidad del vocablo, para emprender una cabalgata bosquejada, apenas planificada. Un criollo del común le indicó con firmeza a Avalario Coria, volviéndose desde el almacén de Chapar, "que ahí quedaban todos los masones muertos", que no eran otra cosa que una isla de hombres en un mar rojizo de mujeres y niños. Entre los 36 muertos hubo criaturas degolladas -algunas nativas, hijas de extranjeros-, las que trasladan la imagen al incendio de un campo inmenso para matar una serpiente.

No hemos hallado documentación que pruebe, antes de 1872, manifestaciones xenofóbicas contra ese colectivo pirenaico cuyos espacios de sociabilidad eran, además, abiertos. Si hubo alguna incomodidad con los vascos -aunque también con sembradores daneses- fue en el grupo poderoso que controlaba el partido y su representante, Adolfo Figueroa. Desde antes de 1860 los pirenaicos avanzaban a paso firme en todos los terrenos, incluso el político, eclipsando desde la corporación municipal, la figura cuasifeudal del juez de Paz (Irianni, 2010). Gerónimo Solané, acusado y sentenciado verbalmente por la turba la misma mañana de los asesinatos, ${ }^{35}$ atendía personalmente a la española Rufina Pérez y tenía como colaborador directo a Juan Lisazo, vasco francés. ${ }^{36}$ También aparecen a lo largo del Sumario e incluso en la bibliografía mencionada, nombres de extranjeros que concurren a curarse en Tapalqué y luego en Tandil.

Tres años antes de las matanzas, según el Primer Censo Nacional, ${ }^{37}$ Tandil contaba con 4870 habitantes, y dentro de los 471 españoles y franceses, 266 eran vascos. Estos últimos eran visualizados como "buenos vecinos". ${ }^{38}$ Los vascos "monopolizaron" algunos oficios y trabajos, entre los que destacan

35 De los catorce detenidos llamados a declarar, sólo dos adujeron conocer a Tata Dios por haber ido a solicitar remedios a su rancho hospital. Declarando dos semanas después de haber muerto Gerónimo Solané, se mantiene la ausencia de señalamiento de culpabilidad hacia el curandero, aunque sí es recurrente el nombramiento como organizador e instigador de Jacinto Pérez.

${ }^{36}$ Casi todos los testigos llamados a declarar, principalmente aquellos que concurrieron al rancho hospital mencionan a Lisazo, Ayúa y un tal Marcos, este último encargado de cuidar el caballo bayo del curandero. Sumario.

${ }^{37}$ Cédulas Censales pertenecientes al partido de Tandil. Primer Censo Nacional, 1869. Sala X. AGN, Argentina.

${ }^{38}$ Irianni (1996, pp. 85-110). Se alude en ese escrito, el rol de vecino -montando el escenario inacabado- subsumiendo al de extranjero, lo que aceleró la integración y apuntaló una imagen positiva para ese grupo étnico. 
40 comerciantes -principalmente en el ámbito rural-, las primeras fondas, la carpintería y zapatería, los hornos de ladrillo, las carretas y la lechería. Eran partidarios de instalar almacenes de ramos generales, los que solían incluir recambio de caballos y servicio de fonda. Pero lo que los catapultó a patrimonios impensados fue sin duda el acopio de cueros y lana, a veces de mano de hacendados cuyas peonadas consumían a cuenta de dicha operación e incluso cobraban sus jornales en esos comercios. Juan Chapar era uno de ellos y los hacendados que vivían en cercanías de su almacén ${ }^{39}$ debieron hacer uso y abuso de aquellas prácticas precapitalistas. ¿Por ello los asesinos saltaron aquella mañana de almacén en almacén (como caballos de ajedrez), con la licencia para robar alguna pilcha o bebidas?, ¿era una estrategia para llegar prontamente $^{40}$ al comercio de Chapar donde no sólo robaron al menudeo sino que rompieron los libros de cuenta, dando allí mismo término al juicio final?

Esta idea, que aquella misma mañana apuntaló el alcalde Urraco al ser observado por un testigo ${ }^{41}$ levantando los libros rotos -aunque legibles-, aleja la categorización de xenofobia al episodio. De ser así, hubo un aprovechamiento de dirigentes y terratenientes locales de cierto sentimiento de injusticia entre criollos y extranjeros que merodeaba la región y la aldea para alcanzar fines particulares. Una arista aparentemente desapercibida del concepto de xenofobia aparece frente al caso aquí analizado. Nos alerta que puede germinar en un grupo poderoso nativo -solemos imaginar sujetos marginales- y convocar a sujetos históricos social y económicamente más débiles -aunque místicos-, para llevarlo a cabo. Podemos graficarlo como un grupo de senadores enviando a sus clientes a amedrentar a un plebeyo (Chapar) que había progresado materialmente y les había prestado dinero, aunque no precisamente para una campaña contra los galos. Si no era manifiesta ni materializada en acciones cotidianas una fricción étnica, ¿se trató de xenofobia?

39 Ramón Gómez, Urraco, Figueroa, Santamarina y Machado, tenían sus campos alrededor del almacén de Juan Chapar. Véase mapa del itinerario de Nario (1976) en apartado El suceso.

${ }^{40}$ Sin detenerse en la infinidad de ranchos y pequeñas parcelas donde era sabido que habitaban extranjeros, convirtiendo el juicio final -de antemano- en selectivo.

${ }^{41}$ Los libros, parcialmente rotos, fueron tomados por Urraco, declara un testigo de apellido Chacón, llegado al lugar antes que el alcalde. Sumario, f. 342. Urraco declara reconocer y haber visto a Chacón, oportunidad en que lo mandó a sellar las puertas del almacén de Chapar. Hacía seis años que la ley obligaba a llevar registro de los acopios en los comercios como el de Chapar. Ni Urraco, Santamarina, los Gómez o Figueroa, desconocían ese trámite sustancial en la tan rudimentaria como sencilla contabilidad de sus oikos. Urraco y Figueroa, como funcionarios, ni el juez que llegó de Buenos Aires podían obviar la búsqueda y en su faltante el rastreo de esos libros. 
Si el motivo -montaje- de semejante episodio fue económico, los poderosos locales igual pudieron mandar a asesinar a un criollo adinerado convocando muchos criollos e hilvanando una serie de muertes en el derrotero para confundir a la opinión pública y la justicia.

La información es, salvo desde el Sumario en cuestión, insuficiente para desentrañar la motivación de medio centenar de individuos, buena parte, foráneos. Por esta última razón, porque Solané había fallecido antes del momento de las declaraciones ${ }^{42}$ y porque nadie menciona encono personal ni colectivo con los extranjeros limitándose a repetir la arenga contra gringos y masones de Jacinto Pérez, podemos debilitar el carácter xenofóbico del episodio. Entre las declaraciones, algunas pasan desapercibidas por su rigidez y parquedad, pero otras destacan en el conjunto. Una de ellas, cara a este trabajo, pertenece a Cruz Gutiérrez. ${ }^{43}$ A lo largo del Sumario y hasta el momento mismo de su fusilamiento el 13 de septiembre en la plaza central de Tandil, Gutiérrez manifiesta una sinceridad incuestionable. No se denota ningún intento de minimizar su accionar, al punto de pedir -una vez apresado-que lo maten por lo que hizo. ${ }^{44} \mathrm{El}$ elemento más importante que aporta entre sus respuestas es, sin duda, que "luego de dar vivas en la plaza y soltar un preso fueron a lo de Chapar". ${ }^{45}$ Esa frase en un forastero -que no conoce cada rincón ni dónde habitan los inmigrantes-, nos indica que el almacén de Chapar a cuatro leguas desde donde inician el raid, era el objetivo principal señalado por el ideólogo de la empresa. Gutiérrez agrega, probablemente sintiéndose engañado, que aquella madrugada en Tandil no estaban las personalidades que según Pérez los esperarían. ${ }^{46}$ Tampoco los indígenas que el adivino aseguró que llegarían a colaborar. A las cuatro de la mañana, antes de comenzar las matanzas, aquel juntador de caballos dudó de un juicio final matando extranjeros sopesando que la plaza estaba rodeada de inmigrantes descansando, pero ellos marcharon a la zona rural. Como Pedro, negando tres veces al me-

${ }^{42}$ Pese a que uno de los involucrados, Ramón Gómez, lo fue a buscar a otro pueblo para que se instale en su establecimiento, Tata Dios se negó a declarar delante del mandatario local, cuñado de Gómez y cuyo campo también lindaba con lo de Chapar. Prefirió esperar el juez que vendría de Buenos Aires. Aquel tardó demasiado, dos semanas, sobrando tiempo para que ultimasen al curandero la Noche de Reyes, encerrado en su calabozo.

${ }_{43}$ Crescencio Montiel, alias Cruz Gutiérrez. Sumario, f. 28. Munfit, Argentina.

${ }_{44}$ Florencio Montero. Sumario, f. 193. MUhfiт, Argentina.

${ }_{45}$ Crescencio Montiel, alias Cruz Gutiérrez. Sumario, f. 29. Munfit, Argentina.

${ }^{46}$ Crescencio Montiel, alias Cruz Gutiérrez. Sumario, f. 30. MuHrit, Argentina. 
sías en unas horas, Cruz Gutiérrez terminaría de confirmar el engaño cuando a media mañana se encontrasen con la guardia armada, que no era romana.

El recorrido de las matanzas recuperado con claridad a partir de las respuestas de los involucrados -desde el mismo momento en que son levados compulsivamente-, es vital. "[...] que retirándose de noche para su casa fue encontrado en el campo por un tal Molina y un tal Jacinto a quien llamaban San Francisco y este le dijo que era necesario lo acompañase al día siguiente y a pesar de que el declarante hizo oposición lo obligaron a ir con ellos, llevándolo a donde estaba una reunión de gente del otro lado de Peñalverde". ${ }^{47}$

Junto a respuestas como la de Villareal que confirman resistencia a participar, las declaraciones en su conjunto conforman trazos esclarecedores del episodio a lo largo del Sumario. Queda claro que no fue necesario atomizar a los 50 criollos para ampliar geográficamente el juicio final que anunciaba Pérez, tan claro como que eran innecesarias más de cinco personas para ultimar a un grupo de trabajadores durmiendo bajo sus carretas o una familia en un almacén. ¿Para qué despertar a medio pueblo a las cuatro de la mañana anunciando lo que harían si no contaban con el apoyo anunciado por el adivino? Era esperable una improvisada persecución de las fuerzas policiales. No es descabellado pensar -como prueba la tranquilidad de los asesinos que relatan los testigos en el momento del encuentro con la policía- que Jacinto Pérez contase con algún guiño luego diluido de personas influyentes del pueblo. "en lo de Chapar saquearon y robaron la casa de negocios y se fueron en seguida a lo de Santa Marina a mudar caballo y hecha esta operación se pusieron en marcha nuevamente $[. .$.$] y allí fueron alcanzados inmediatamente por la fuerza que$ salió de este Pueblo en persecución habiéndose dispersado todos sin pelear" ${ }^{48}$

Es inexplicable, salvo desde el efecto terrorista que brinda medio centenar de criollos al galope y gritando muertes en medio de la noche, la conformación de aquel grupo. El mayor número de víctimas, 18 en lo de Juan Chapar, estaba compuesto por un porcentaje importante de mujeres y criaturas junto a un par de hombres desarmados. Dos grupos de carreteros vascos, que sumaban 16 individuos, fueron sorprendidos una hora antes de llegar al último almacén durmiendo a 20 cuadras del corazón del pueblo. Aquellos criollos no fueron "levados" -tal como se desprende de la actitud de los reos al encontrarse con los perseguidores-, a efectos de repeler un ataque posible

${ }^{47}$ Claudio Villareal. Sumario, f. 43. MUHFit, Argentina.

${ }^{48}$ Juan Arballo. Sumario, fs. 60-61. MUHFIT, Argentina. 
de la milicia. La mayoría de los involucrados actuó empujado por el contexto, en parte obligados por un temerario puñado de hombres de armas tomar. Algunos, disimulando a media mañana con algarabía haber cumplido con Dios y la patria, matando masones aunque no supiesen a ciencia cierta que significaba ese término. Muchos, presos del pánico al ser tildados públicamente de mentirosos por Tata Dios, quien supuestamente los había enviado a cumplir esa misión. Varios -alrededor de $22-{ }^{49}$ alcanzaron a escapar. Como sea, en una neblina de confusión y desamparo, ninguno presentó batalla. Jacinto Pérez conformó un escuadrón de falsos cristinos con el propósito de ultimar a un vasco de dudosa filiación carlista.

después fueron a la casa de un tal Chapar [...] en seguida fueron a mudar caballos a lo de Santamarina. ${ }^{50}$

de lo de Chapar fueron a la estancia de Santa Marina a mudar caballos los que encontraron ya en el corral, ignorando quién los encerraría y por orden de quién. ${ }^{51}$

Algunos implicados declaran que luego de lo de Chapar fueron a lo de Santamarina, donde los esperaba una caballada de refresco. ¿Era para que huyeran del pueblo y de la ley antes de hablar?, ¿cuánto personal, acaso capataces como Juárez que observa Urraco sabían de aquellos animales atados -en un número inusual- sin dar parte a su dueño? Con la relación consabida entre animal y jinete en la pampa, ¿estaban aquellas personas dispuestas a dejar su caballo por uno desconocido, incluso de menor calidad en el apuro?, ¿fue otro momento de improvisación o acaso no informado para evitar deserciones?

\section{A MODO DE CIERRE. HACHAR EL ROBLE}

Este caso aporta un elemento inusual al fenómeno en estudio: espontaneidad compulsiva. Aquello dista del grupo de individuos irritados contra un

49 Sumario, f. 15. MUHFIT, Argentina. El listado, quizá incompleto, se recompone a partir de certezas y suposiciones sobre sus identidades desde las declaraciones de los apresados y testigos.

50 Crescencio Montiel, alias Cruz Gutiérrez. Sumario, f. 30. MUHFIT, Argentina.

51 Pedro Torres. Sumario, f. 39. MUHFit, Argentina. 
extranjero que se niega a pagarles el servicio de doma ya realizado o intenta cobrarles una deuda antes saldada. El temor a no participar de varios criollos acompañados a la reunión de la noche vieja por hombres armados es crucial. La elección de una etnia regional a los pies de una torre de Babel como era la aldea tandilense es decisiva, máxime cuando sólo atacaron a carreteros y almaceneros (siendo que había personas de otras nacionalidades en esas ocupaciones y vascos en otros trabajos) que llamativamente no competían con el criollo pobre en sus quehaceres.

Aquel día, el vecindario tandilense observó la erupción de procesos que pugnaban estallar desde 1860. Un episodio confuso toda vez que reúne elementos que dificultan su esclarecimiento, aun luego de transcurrido y delante de la documentación que nos lega. Ocultos en el seno de medio centenar de criollos arrastrados por la fuerza, cuatro o cinco personas asesinaron a una treintena de extranjeros, entre los que predominaron vascos. Es altamente probable que lo hiciesen -tras una arenga mística que cubriese el objetivo principal-, incitados por individuos poderosos que debían dinero en el almacén de Chapar antes de que inaugurase ese mismo 1 de enero la sucursal del Banco Provincia. Aquello daba por tierra con una vieja práctica -arraigada en torno a los vascos-, de negocios bajo palabra y apretón de manos. El libro de cuentas dañado, pero no destruido, del almacén de Chapar -aunque tampoco presentado a la justicia por el teniente alcalde Urraco- es elocuente, máxime si en los comercios anteriores los implicados no se ocuparon ni percataron de los registros contables.

La turba también se movilizó porque Jacinto Pérez dijo -tomando palabras del cura Rodríguez-, que extranjeros y masones eran lo mismo. No fue el párroco quien agregó oportunamente el gentilicio de vascos, sino quienes señalaron ese objetivo al ideólogo Pérez. Los gritos que escucha el vecindario detrás de sus postigones y repiten los apresados frente al juez, direccionan el accionar hacia un acto de apariencia tan xenofóbico como de cruzada religiosa. "Mueran siendo gringos y masones -mueran siendo vascos-, que pisotean la religión y al paisanaje." La adhesión de un grupo que no se conoce entre sí, para participar en un pueblo ajeno -compulsivamente- de una matanza que busca sellar un ajuste de cuentas económico de terceros, aleja al suceso de los fundamentos teóricos sobre xenofobia. El móvil místico que luego de una arenga general contra extranjeros escoge víctimas específicas de una etnia y determinados oficios, no colabora en pos de rotularlo como xenofóbico. 
Tildar el episodio como un ensayo de xenofobia rural o fronterizo tampoco representa cabalmente lo sucedido, pero lo ubica temprano en el tiempo y eso colabora en la observación de que aquellos conflictos espasmódicos debieron estar apuntalados por una coyuntura socioeconómica asfixiante. La situación tensa era real, pero los causantes de la misma no eran un problema para los hombres armados esa mañana, sino para los deudores de una de las víctimas. No hay, llamativamente, estereotipo de inmigrante asentado en la pampa que resulte mejor ponderado en la memoria popular y la literatura que el vasco. La referencia al escenario fronterizo no es menor, dado que luego se impondrán ejemplos citadinos y tardíos.

El aporte historiográfico de este trabajo, utilizando en parte el Sumario confeccionado con declaraciones de los implicados en las matanzas, testigos, algunos comisarios y abogados, radica en nuevos enfoques y miradas a la documentación. También a esa amplitud focal que incluya la totalidad potencial de los actores inmersos en el escenario regional y local, aunque no estuviesen comprometidos en el episodio. Las respuestas al interrogante sobre la xenofobia asumida anteriormente sin mayor problematización aparecen -como hemos visto- en pasajes específicos de involucrados como Cruz Gutiérrez. Sin embargo, una mirada general a las declaraciones es lo que mina cualquier pretensión de categorizar como xenofóbico el episodio. Recordemos las que aseguran compulsión manifiesta a una reunión y luego a tomar armas. También la de ese puñado de criollos implicados que se animó a aminorar la marcha o desertar en la complicidad de la oscuridad y el polvo de la caballada. Los matadores fueron unos pocos -los que iban en la vanguardia-, los mismos que arrearon hombres solos -en buena parte foráneos- a la reunión en el rancho de Pérez. Los jinetes señalados como aquellos "que mataban en cada sitio antes de que llegara el resto", fueron ejecutados inesperada y espasmódicamente por miembros de la partida cuando regresaban de lo de Chapar. Llamativamente, el teniente alcalde Urraco fue quien mandó cargar a degüello sobre unos victimarios atónitos, armas abajo y semblantes de festejo por sus logros de haber terminado con el enemigo de la patria y la religión.

El itinerario de la matanza, que llamativamente los ideólogos no se percataron de disimular, no es un dato de menor valía para diluir el rótulo de acto xenofóbico a secas. El asesinato de carreteros de paso por el pueblo y almaceneros que difícilmente fiaran a criollos pobres, representa los casilleros elegidos por los jinetes para llegar antes del amanecer a lo de Chapar. Esa cabalgata inexplicable de cuatro leguas apenas disimulada con la muerte de dos 
italianos -un hombre al dejar la plaza y un niño que ayudaba en un almacén-, parecen ampararse en una impunidad que se rompe en mil pedazos al encontrarse con una partida retrasada que disimulaba urgencias.

El último acto se desenvuelve en un almacén de ramos generales de vascos cuyo fuerte consistía en el acopio de cueros y lanas. Era apenas un pequeño espacio autárquico rodeado de estancias -con muchas deudas- de aquellos que organizaron, liberaron zonas, silenciaron testigos como Solané y la esposa de Jacinto Pérez. Romper los libros de cuentas en la última estación de la cabalgata, luego de estar en otros almacenes, fue la idea que permitió imaginar el libreto del drama, con un par de actores principales y el resto de reparto. ¿Para qué reunir medio centenar de hombres supuestamente diestros con el cuchillo, según indica la procedencia rural y gauchesca de varios, si huyeron al encontrarse con la milicia?

No es menor discutir un acto xenofóbico contextualizado en una época y lugar donde la violencia era parte visible, casi pública, de la vida cotidiana. ${ }^{52}$ En ese sentido, un cambio de paisaje materializado en el paso de la estancia vacuna, extensiva y obligadamente ecuestre a una lanar, mayormente familiar, desplazaba gauchos y hacía trastabillar terratenientes absentistas que no manipulaban dinero. El acorralamiento del papa a un territorio diminuto en la península itálica en 1870 no fue un rumor con forma de brisa, sino un ventarrón de palabras que recorrieron occidente. En esa coyuntura, resulta difícil -aun cuando fuese un episodio aislado-, no relativizar la posibilidad de que aquella matanza de extranjeros en Tandil se catalogue como un episodio xenofóbico. Tampoco se acerca a una persecución religiosa o intolerancia toda vez que está probada la religiosidad en una mayoría vasca. ${ }^{53} \mathrm{El}$ alto porcentaje de víctimas pirenaicas según sus oficios replica un ajuste gremial propio del medioevo y no suma -todo lo contrario- elementos xenófobos.

Las matanzas del Tandil no pueden catalogarse de episodio xenofóbico a secas. En un espectro de rótulos blancos y negros, reúne demasiados grises. No descartamos que el malestar pampeano observado por José Hernández

${ }^{52}$ Véase Yangilevich (2012, caps. In y vi). Los actos violentos de un tal Migues con el danés Fugl, están descritos en sus memorias. Fugl (1874/1989). Dado que se trata de un criollo violento, poco amistoso con el vecindario, nadie sugirió que aquello fuese xenofobia.

${ }^{53}$ Es indispensable aclarar que los masones no eran ateos, todo lo contrario. Aquellos criticaban cierta continuidad medieval de la Iglesia que se oponía a la ciencia, pero también la cantidad de tierras y edificios que habían acumulado durante siglos en buena parte de occidente. La desamortización en España es evidente, tanto como la presión y arrinconamiento en Italia. 
pudo -sumado a las compulsiones y temores comentados- movilizar intenciones xenofóbicas en algunos criollos. De todos modos, aquellas debieron tener una magnitud y densidad insuficientes para que se desaten espontáneamente. El fin de este sendero sinuoso de un bosque por el que nos guiaron la historia problema y la información del Sumario culmina en un ejemplar de roble pirenaico de apellido Chapar. Revisando el raid de los asesinos, la metáfora de desmalezar el sendero hasta encontrar un árbol y hacharlo no es descabellada.

\section{LISTA DE REFERENCIAS}

Armus, D. (1984). Notas sobre el impacto inmigratorio ultramarino a la Argentina y la visión de los protagonistas. Revista de Indias, 44(174), 489-504.

Bestene, J. (1994). La inmigración sirio-libanesa en América Latina. Realidades y estereotipos: los "turcos" en el teatro argentino. Estudios Migratorios Latinoamericanos, 9(26), 143-164.

Clementi, H. (1984). El miedo a la inmigración. Buenos Aires, Argentina: Leviatán.

Ébelot, A. (1890/2001). La pampa. Costumbres argentinas. Buenos Aires: Taurus.

Fradkin, R. y Gelman, J. (2004). Recorridos y desafíos de una historiografía. Escalas de observación y fuentes en la historia rural rioplatense. En B. Bragoni (ed.), Microanálisis. Ensayos de historiografía argentina. Buenos Aires: Editorial Prometeo.

Fugl, J. (1874/1989). Memorias de un danés en la Argentina, 1844-1875. (Trad. de Alice Larsen de Rabal). Tandil, Argentina.

Gallo, E. (1983). La pampa gringa. Buenos Aires, Argentina: Sudamericana.

Garavaglia, J. (1992). Las relaciones entre el medio y las sociedades humanas en su perspectiva histórica, Anuario IEHS, 7.

Garavaglia, J. (1995). Notas para una historia rural pampeana un poco menos mítica. En M. Bjerg y A. Reguera (comps.), Problemas de la historia agraria. Tandil: IEHS-UNICEN.

Garavaglia, J. (1999). Pastores y labradores de Buenos Aires. Una historia agraria de la campaña bonaerense, 1700-1830. Buenos Aires: Ediciones de la Flor.

Gori, G. (1964). Inmigración y colonización en la Argentina. Buenos Aires, Argentina: EUDEBA.

Irianni, M. (1996). Buenos vecinos. Integración social de los vascos en Tandil, 1840/1880. Estudios Migratorios Latinoamericanos, 32, 85-110.

Irianni, M. (1997). Trabajadores vascos en el recuerdo popular rioplatense. Revista de Indias, 57(210), 399-419. DoI: https://doi.org/10.3989/revindias.1997.i210.784 
Irianni, M. (2010). Historia de los vascos en la Argentina. Buenos Aires: Editorial Biblos (Colección La Argentina Plural, dirigida por Fernando Devoto).

Irianni, M. (2017). Mariposas en la tormenta. La matanza de extranjeros en un valle pampeano, Tandil, 1872. Studi Emigrazione, 54(206), 324-337.

Jong, I. de (2016). Prácticas de la diplomacia fronteriza en las Pampas, siglo xIx. Habitus, 14(2), 175-197. DoI: http://dx.doi.org/10.18224/hab.v14.2.2016.175-197

Lida, C. (1998). Inmigración, etnicidad y xenofobia en la Argentina: la masacre de Tandil. Revista de Indias, 58(214), 541-554. DoI: https://doi.org/10.3989/revindias.1998.i214.747

Liernur, P. (1984). Buenos Aires. La estrategia de la casa autoconstruida. En A. Diego et al., Sectores populares y vida cotidiana, Buenos Aires: CLAcso.

Lynch, J. (2001). Masacre en las pampas. La matanza de inmigrantes en Tandil (1872). Buenos Aires, Argentina: Editorial Emece.

Macagno, L. (2002). Apocalipsis al Sur. Una protesta contra inmigrantes en el "desierto" argentino. Buenos Aires, Argentina: Editorial Biblos.

Mandrini, R. (1992). Indios y fronteras en el área pampeana (siglos XVI-XIX). Balance y perspectivas. Anuario IEHS, 7, 59-72. Recuperado de http://anuarioiehs.unicen. edu.ar/1992.html

Mandrini, R. (1997). Las fronteras y la sociedad indígena en el ámbito pampeano. Anuario IEHS, 12, 23-34. Recuperado de http://anuarioiehs.unicen.edu.ar/1997. html

Mayo, C., Amaral, S., Garavaglia, J. C., Gelman, J. et al., (1987). Estudios sobre el mundo rural polémica: gauchos, campesinos y fuerza de trabajo en la campaña rioplatense colonial. Anuario IEHS, 2, 21-60. Recuperado de http://anuarioiehs. unicen.edu.ar/1987.html

Míguez, E. (1987). Política, participación y poder. Los inmigrantes en las tierras nuevas de la provincia de Buenos Aires en la segunda mitad del siglo xix. Estudios Migratorios Latinoamericanos, 6/7, 337-379.

Moya, J. (1989). Parientes y extraños: actitudes hacia los inmigrantes españoles en la Argentina del siglo xIX. Estudios Migratorios Latinoamericanos, 13, 499-523.

Nario, H. (1976). Tata Dios. El mesías de la última montonera. Buenos Aires, Argentina: Plus Ultra.

Oddone, N. y Granato, L. (2007). La matanza de los inmigrantes de Tandil en 1872. Un Estado Nacional no consolidado. Entelequia. Revista Interdisciplinar, 4, 29-53. Recuperado de https://revistaentelequia.wordpress.com/2007/06/01/la-matanza-de-los-inmigrantes-en-tandil-de-1872-un-estado-nacional-no-consolidado/ 
Onega, G. (1982). La inmigración en la literatura argentina (1880-1910). Buenos Aires, Argentina: CEAL.

Páez, J. (1976). El Conventillo. Buenos Aires, Argentina: CEAL.

Palermo, M. (1978). Fin del mundo en Tandil. Punto de Vista, 1, 8-13.

Ratto, S. (2003). Cuando las fronteras se diluyen. Las formas de interrelación blanco-indias en el sur bonaerense. En R. Mandrini y C. Paz (comps.), Las fronteras hispanocriollas del mundo indígena latinoamericano en los siglos XVIII-XIX. Un estudio comparativo. Tandil: IEHS/CEHIR/UNS.

Rodríguez Molas, R. (1982). Historia social del gaucho. Buenos Aires. Argentina: CEAL.

Sábato, H. (1983). ¿Trabajar para vivir o vivir para trabajar? Empleo ocasional y escasez de mano de obra en Bs. As., ciudad y campaña, 1850/1880. Primeras Jornadas de Historia Argentina y Americana, Tandil, Argentina, UNCPBA.

Sábato, H. (1985). La formación del mercado de trabajo en Buenos Aires, 1850-1880. Desarrollo Económico, 24(96), 561-592.

Santos, J. J. (1995). Una revuelta rural en la frontera sur bonaerense: Tandil, 1872. Buenos Aires, Argentina: EudEBA.

Santos, J. J. (2008). El Tata Dios. Milenarismo y xenofobia en las pampas. Buenos Aires, Argentina: Editorial Sudamericana (Colección Nudos de la Historia Argentina).

Scobie, J. (1977). Buenos Aires: Del centro a los barrios, 1870/1910. Buenos Aires, Argentina: Ediciones Solar.

Scobie, J. (1982). Revolución en las pampas. Historia social del trigo argentino, 1860-1910. Buenos Aires, Argentina: Ediciones Solar.

Seefeld, R. (1984). La integración social de extranjeros en Buenos Aires. ¿Pluralismo cultural o crisol de razas, 1860/1923? Jornadas sobre Inmigración, Pluralismo e Integración, Buenos Aires, Argentina, 14 y 15 de noviembre de 1984, IDEs.

Seefeld, R. (1985). Un modelo para el análisis de la integración de inmigrantes, el fenómeno de la etnicidad. Primeras Jornadas de Estudios sobre la Inmigración, Ministerio de Cultura y Educación, Buenos Aires, Argentina.

Slatta, R. (1985). Los gauchos y el ocaso de la frontera. Buenos Aires: Editorial Sudamericana.

Suriano, J. (1984). La huelga de inquilinos de 1907. En D. Armus et al., Sectores populares y vida cotidiana. Buenos Aires: Clacso.

Yangilevih, M. (2012). Estado y criminalidad en la frontera sur de Buenos Aires (18501880). Rosario: Prohistoria ediciones.

Wolf, E. et al. (2001). La gran inmigración. Buenos Aires, Argentina: Editorial Sudamericana. 


\section{OTRAS FUENTES}

Archivos

AGN Archivo General de la Nación, Argentina.

AHM Archivo Histórico Municipal, Argentina.

AhP Archivo Histórico Provincial, La Plata, Argentina.

muhfit Archivo del Museo Histórico del Fuerte Independencia de Tandil, Argentina. 